\title{
PREVALENCE OF VIM- AND GIM-PRODUCING ACINETOBACTER BAUMANNII FROM PATIENTS WITH SEVERE URINARY TRACT INFECTION
}

\author{
SMILINE AS GIRIJA ${ }^{1 *}$, VIJAYASHREE PRIYADHARSINI JAYASEELAN ${ }^{2}$ and \\ PARAMASIVAM ARUMUGAM ${ }^{3}$ \\ ${ }^{1}$ Department of Microbiology, Saveetha Dental College and Hospitals, Saveetha Institute \\ of Medical and Technical Sciences (SIMATS), Chennai, India \\ ${ }^{2}$ BRULAC-DRC, Saveetha Dental College and Hospitals, Saveetha Institute of Medical \\ and Technical Sciences (SIMATS), Chennai, India \\ ${ }^{3}$ Department of Human Genetics, Centre for Cellular and Molecular Biology, \\ Hyderabad, India
}

(Received: 21 May 2018; accepted: 12 June 2018)

\begin{abstract}
Carbapenems are administered as the final drug of choice for treating complicated nosocomial infections caused by multidrug-resistant Acinetobacter baumannii strains. It is currently a worldwide issue that metallo- $\beta$-lactamases (MBLs) as carbapenem-hydrolyzing enzymes are one of the major drug resistance mechanisms. This investigation is thus aimed to assess the prevalence and characterize the MBL-producing strains of $A$. baumannii both by phenotypic assays and by genotypic characterization. A total of 73 isolates of $A$. baumannii were phenotypically and genotypically characterized from patients $(N=1,000)$ with severe urinary tract infection. Tested strains were subjected to double disc synergy testing (DDST) by Kirby-Bauer disc diffusion method with imipenem (IMP) and IMP/EDTA combination discs. Plasmid DNA was molecularly screened for MBL-encoding $b l a_{\mathrm{IMP}}, b l a_{\mathrm{VIM}}$, $b l a_{\mathrm{GIM}}$, and $b l a_{\mathrm{NDM}}$ genes by PCR for the genetic relatedness of the MBL genes with carbapenem resistance. Carbapenem resistance profile showed $100 \%, 45 \%$, and $49 \%$ non-susceptibility against imipenem, doripenem, and meropenem, respectively. Altogether $42.46 \%(n=31)$ of the isolates showed MBL production upon double disc phenotypic test with IMP and IMP/EDTA discs. The $b l a_{\mathrm{VIM}}$ and $b l a_{\mathrm{GIM}}$ were detected in $34.24 \%(n=25)$ and $16.43 \%(n=12)$ of the isolates, respectively, while the co-occurrence of $b l a_{\mathrm{VIM}}$ and $b l a_{\mathrm{GIM}}$ was $2.73 \%$ among the isolates. DDST-positive isolates showed $21.19 \%$ and $9.58 \%$ strains positive for $b l a_{\mathrm{VIM}}$ and $b l a_{\mathrm{GIM}}$, respectively, whereas $1.36 \%$ of the strains for both genes. None of the strains yielded $b l a_{\mathrm{IMP}}$ and $b l a_{\mathrm{NDM}}$ genes. The findings of this study showed prevalence of carbapenem resistance among $A$. baumannii from urine samples and the frequency of $b l a_{\mathrm{VIM}}$ and $b l a_{\mathrm{GIM}}$.
\end{abstract}

Keywords: $A$. baumannii, carbapenems, $b l a_{\mathrm{IMP}}, b l a_{\mathrm{VIM}}, b l a_{\mathrm{GIM}}, b l a_{\mathrm{NDM}}$

*Corresponding author; E-mail: smilinejames25@gmail.com 


\section{Introduction}

Acinetobacter baumannii, a pleomorphic, aerobic Gram-negative bacterium, has emerged as one of the critical multidrug-resistant nosocomial pathogens worldwide [1]. A. baumannii is considered as one among the top seven pathogens threatening the patient's healthcare and as an unmet medical need [2]. A. baumannii infections are considered with great concern due to their resistance pattern exhibited to several classes of antibiotics, especially carbapenems [3] and are considered as sentinels of drug resistance with the designation as carbapenemresistant A. baumannii [4]. Among several mechanisms related to carbapenem resistance, the resistance exhibited due to carbapenem-hydrolyzing enzymes is frequently considered worldwide [5]. Based on the Ambler classification, these enzymes belong to class B metallo- $\beta$-lactamase (MBL) and class D OXA-type carbapenemases and most of them are mediated by plasmids [6].

MBLs are further classified into several families with $b l a_{\mathrm{VIM}}, b l a_{\mathrm{IMP}}$, $b l a_{\mathrm{GIM}}$, and more recently $b l a_{\mathrm{NDM}}$ and are located in the gene cassettes of class 1 integrons with $b l a_{\mathrm{IMP}}$ in class 3 integrons [7, 8]. For the optimal MBL activity, divalent cations are required as cofactors with further action of one or two zinc ions for their catalytic activity with chelators as inhibitory agents [9]. These MBLs are highly potent in hydrolyzing all the $\beta$-lactam antibiotics except the monobactams such as aztreonam [10] and there are no known MBL inhibitors [11]. Dissemination of MBL-encoding genes is highly popular among the plasmids or by integron-borne mobile gene cassettes through horizontal gene transfer mechanisms [12]. As a dominant MBL variant, bla $a_{\mathrm{NDM}}$ [13] and bla $a_{\mathrm{VIM}-2}$ [14] have recently emerged with worldwide reports.

Earlier studies have reported the emergence of $b l a_{\mathrm{VIM}^{-}}, b l a_{\mathrm{IMP}^{-}}$, and $b l a_{\mathrm{GIM}^{-}}$ based carbapenem resistance among $A$. baumannii $[15,16]$ along with the increased incidences of $b l a_{\mathrm{NDM}}$-based resistance $[17,18]$. Detection of these MBLs is often based on the inhibitor-based test using metal ion chelators, such as ethylene diamine tetra acetic acid (EDTA) or thio-based compounds [19]. Among several phenotypic detections, Clinical Laboratory Standards Institute (CLSI) [21] advocates the application of modified Hodge's test, CarbaNP test, and/or a molecular-based assay for the confirmation of the MBL producers among Enterobacteriaceae and A. baumannii strains. Genotypic characterization of the MBL-based genetic determinants $b l a_{\mathrm{VIM}}, b l a_{\mathrm{IMP}}, b l a_{\mathrm{GIM}}$, and $b l a_{\mathrm{NDM}}$ is detected by polymerase chain reactions (PCRs) and clonal relatedness is analyzed by various molecular methods [20].

With this background, the present investigation aimed to phenotypically and genotypically characterize the MBL producers among $A$. baumannii strains with the phylogenetic assessment of the MBL-based genetic determinants such as 
$b l a_{\mathrm{VIM}}, b l a_{\mathrm{IMP}}, b l a_{\mathrm{GIM}}$, and $b l a_{\mathrm{NDM}}$ screened from the patients with severe urinary tract infections from South India.

\section{Materials and Methods}

Study design

A total of 73 consecutive and non-repetitive $A$. baumannii isolates, which were isolated and identified for a period of 12 months (2014-2015) from urine samples of patients with severe urinary tract infections $(N=1,000)$, were phenotypically and genotypically confirmed by conventional microbiological analytical tests and PCR, respectively, at the Department of Microbiology. These characterized strains were subjected to antibiotic susceptibility test by standard KirbyBauer disc diffusion method using imipenem (IMP; $10 \mu \mathrm{g})$, doripenem $(10 \mu \mathrm{g})$, and meropenem $(10 \mu \mathrm{g})$ for the carbapenem resistance profile of the selected strains under study.

\section{Phenotypic confirmatory test}

With the observation and record of the carbapenem resistance, all the strains were further subjected for phenotypic double disc synergy testing (DDST) as per the CLSI (2012) [21]. All the test strains were prepared as fresh broth cultures and lawn was made onto sterile Mueller-Hinton agar (MHA; Hi-Media, Mumbai). For the MBL detection, two discs were used for the profile such as IMP $(10 \mu \mathrm{g})$ (Hi-Media) and IMP/EDTA. An amount of $0.5 \mathrm{M}$ EDTA was prepared by dissolving $186.1 \mathrm{~g}$ of disodium EDTA- $2 \mathrm{H}_{2} \mathrm{O}$ in $1,000 \mathrm{ml}$ of distilled water (pH 8.0) and was sterilized by autoclaving. An amount of $10 \mu \mathrm{l}$ was added onto one of the IMP discs to obtain the desired concentration of IMP/EDTA $(10 / 750 \mu \mathrm{g})$. The discs were placed onto the surface of the MHA at a distance of $20 \mathrm{~mm}$ from each. The plates were then incubated for a period of $24 \mathrm{~h}$ at $37^{\circ} \mathrm{C}$. The increase in zone size of $\geq 7 \mathrm{~mm}$ around the IMP/EDTA disc than IMP was interpreted as MBL producers.

Molecular detection of bla ${ }_{V I M}$, bla $_{I M P}$, bla $a_{G I M}$, and bla $a_{N D M}$ genetic determinants in $M B L$ producers

Extraction of plasmid DNA and PCR amplification. All the strains were stored at $-80{ }^{\circ} \mathrm{C}$ in $80 \% / 20 \%(\mathrm{v} / \mathrm{v})$ glycerol in Luria-Bertani media for genetic stability of 
resistance upon storage [22]. Plasmid DNA was extracted from fresh cultures of $A$. baumannii using Qiagen extraction kit in accordance with the manufacturer's instructions and was stored in $-20{ }^{\circ} \mathrm{C}$ until further use. An amount of $15 \mu \mathrm{l}$ of amplification reaction mixtures was prepared by mixing $7.8 \mu \mathrm{l}$ of $2 \times$ Master Mix (Takara, Japan) in $5.6 \mu \mathrm{l}$ of double distilled water. Specific forward primer and reverse primer (Eurofins Genomic India Pvt Ltd., Bangalore, India) of bla $a_{\mathrm{VIM}}$, $b l a_{\mathrm{IMP}}, b l a_{\mathrm{GIM}}$, and $b l a_{\mathrm{NDM}}$ were added using the standard PCR conditions (Table I). PCR amplification was carried out and the resulting PCR amplicons were examined in $1 \%$ agarose gel electrophoresis containing ethidium bromide, which was visualized in a gel documentation system. The $100 \mathrm{bp}$ DNA ladder was used to confirm the amplicon size.

\section{Results}

Preliminary screening for the carbapenem resistance tests showed $100 \%$, $45 \%$, and $49 \%$ non-susceptibility against imipenem, doripenem, and meropenem, respectively, as per CLSI zone interpretative criteria (Figure 1). DDST with IMP and IMP/EDTA discs yielded $42.46 \%(n=31)$ of the isolates as MBL producers (Table II). A total of 37 isolates $(50.68 \%)$ showed resistance to all the carbapenems tested with $31.50 \%(n=23)$ DDST-positive (Figure 2).

Genotypic characterization of the MBL genetic determinants showed the presence of $b l a_{\mathrm{VIM}}$ and $b l a_{\mathrm{GIM}}$ in $34.24 \%(n=25)$ and $16.43 \%(n=12)$ of the isolates. Co-occurrence of $b l a_{\mathrm{VIM}}$ and $b l a_{\mathrm{GIM}}$ was observed in $2.73 \%(n=2)$ of the isolates. DDST-positive isolates showed $21.19 \%(n=16)$ positive for $b l a_{\mathrm{VIM}}$ and $9.58 \%(n=7)$ positive for $b l a_{\text {GIM }}$ determinants (Table III and Figure 3). Among the two isolates with both $b l a_{\mathrm{VIM}}$ and $b l a_{\mathrm{GIM}}$ genes, only one strain was DDST-positive. However, none of the strains yielded $b l a_{\mathrm{IMP}}$ and $b l a_{\mathrm{NDM}}$ genes.

\section{Discussion}

A wide range of nosocomial infections encompassing meningitis, septicemia, pneumonia, and skin and wound infections are caused by A. baumannii and are considered as a major challenge in the patient healthcare [23]. Carbapenems such as imipenem, doripenem, meropenem, and ertapenem are considered as the last resort antibiotics in the treatment of severe and complicated infections established by multidrug-resistant $A$. baumannii [24]. In recent decades, resistance to carbapenems is highly reported [25]. The present investigation has also recorded a total of 37 isolates $(N=73)$ as carbapenem-resistant strains. All the strains fall under the 


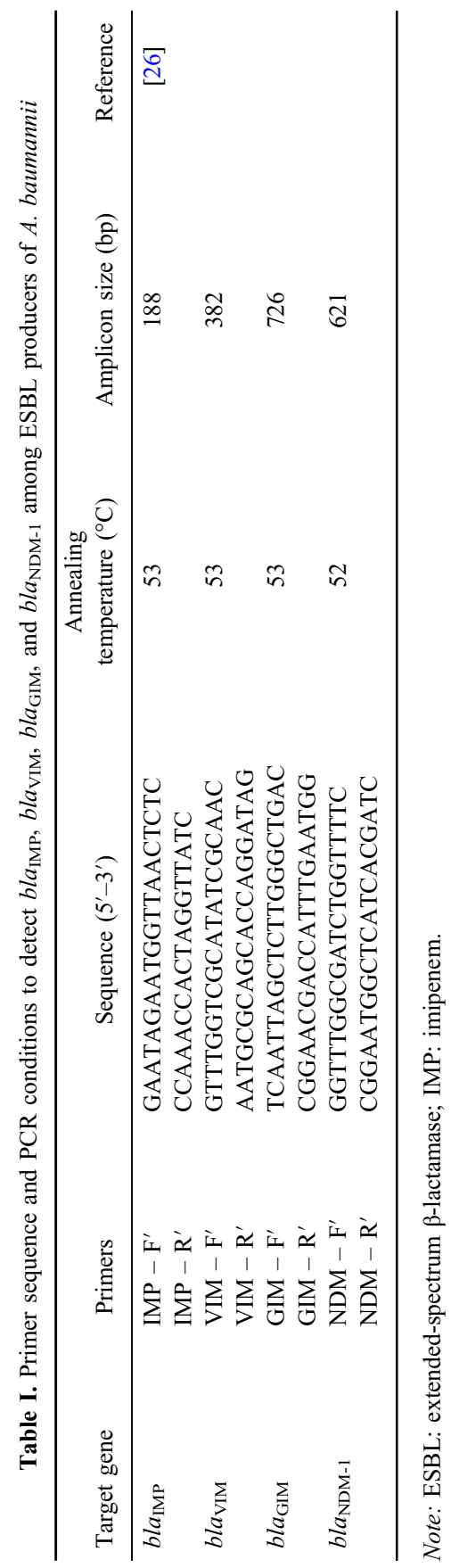




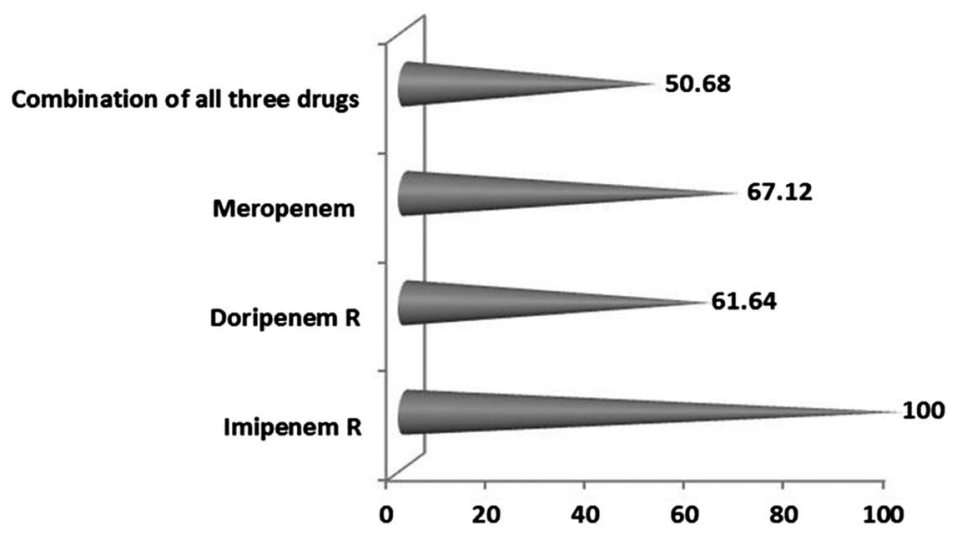

Figure 1. Frequency of resistance exhibited by A. baumannii toward the antibiotics tested

Table II. Preliminary screening and phenotypic confirmation of ESBL producers among the $A$. baumannii isolates as per CLSI (2012) [21]

\begin{tabular}{lccc}
\hline Isolate & Preliminary screening & \multicolumn{2}{c}{ DDST } \\
\hline A. baumannii & $100 \%$ & Antibiotics & Positive $(\%)$ \\
\cline { 2 - 4 }$(N=73)$ & $(n=73)$ & Imipenem and & 41.46 \\
& & imipenem + EDTA & $(n=31)$ \\
\hline
\end{tabular}

Note: ESBL: extended-spectrum $\beta$-lactamase; DDST: double disc synergy test; EDTA: ethylene diamine tetra acetic acid; CLSI: Clinical Laboratory Standards Institute.

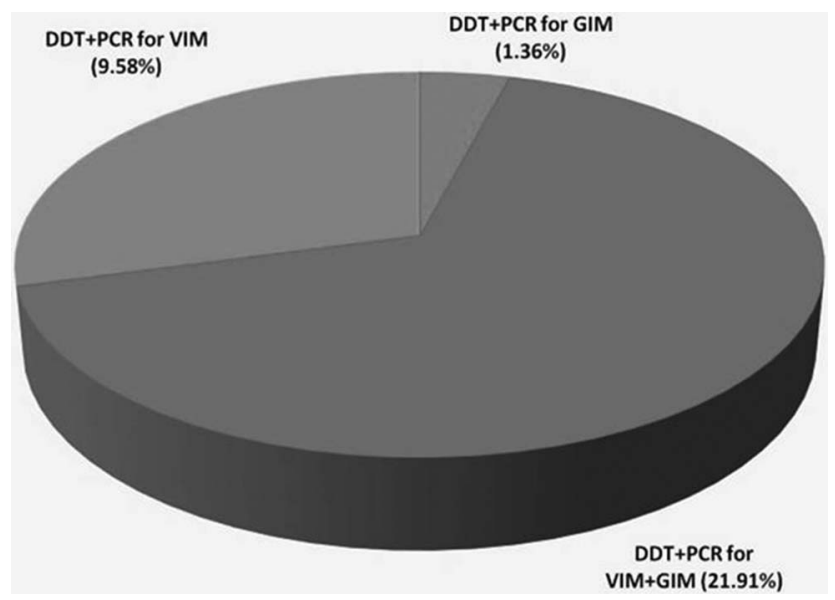

Figure 2. The specificity of detection methods employed for identifying drug-resistant strains 
Table III. Distribution of $b l a_{\mathrm{IMP}}, b l a_{\mathrm{NDM}}, b l a_{\mathrm{VIM}}$, and $b l a_{\mathrm{GIM}}$ genes among the MBL producers of A. baumannii

\begin{tabular}{lccccc}
\hline $\begin{array}{l}\text { MBL-positive } \\
\text { isolates }\end{array}$ & \multicolumn{5}{c}{ Target genes studied $(\%)$} \\
\hline $\begin{array}{l}\text { A. baumannii } \\
(N=73)\end{array}$ & bla $_{\mathrm{IMP}}$ & $b l a_{\mathrm{NDM}}$ & $b l a_{\mathrm{VIM}}$ & $b l a_{\mathrm{GIM}}$ & $b l a_{\mathrm{VIM}}+b l a_{\mathrm{GIM}}$ \\
\cline { 2 - 6 } & 0 & 0 & 34.24 & 16.43 & 2.73 \\
& & & $(n=25)$ & $(n=12)$ & $(n=2)$ \\
\hline
\end{tabular}

Note: MBL: metallo- $\beta$-lactamase.

(a)

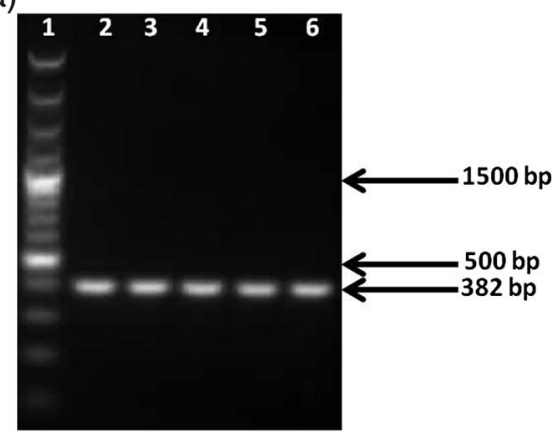

(b)

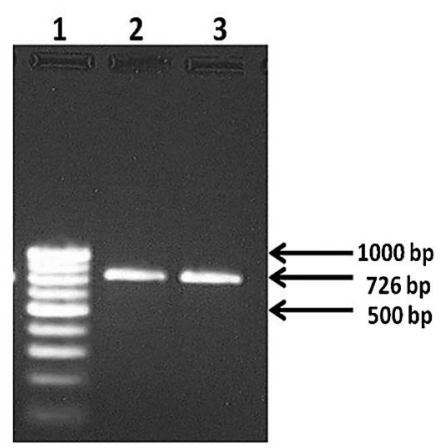

Figure 3. Electrophoretogram of (a) $b l a_{\mathrm{VIM}}$ gene and (b) $b l a_{\mathrm{GIM}}$ amplicons run along with $100 \mathrm{bp}$ DNA ladder (Lane 1)

imipenem-resistant strains of $A$. baumannii. One hundred percent of the strains showing imipenem resistance are also reported in an earlier study from South India [27]. Imipenem showing intrinsic resistance in A. baumannii is reported [28] and in many earlier studies the isolates of $A$. baumannii for carbapenemase and MBL production were categorized based on imipenem susceptibility and resistance patterns [29]. Several studies have recorded the higher incidences of imipenem non-susceptibility/resistance [30, 31]. This study has recorded nearly $60 \%-65 \%$ of non-susceptibility against doripenem and meropenem with only $15.06 \%$ and $13.69 \%$ susceptibility against the same, respectively. Similar observations were recorded from Turkey with $66.6 \%$ resistance against meropenem and $49.9 \%$ against doripenem [32]. Another study from USA showed $68 \%$ and $80 \%$ nonsusceptibility to meropenem and doripenem, respectively [33]. On the contrary, an earlier study from Punjab recorded only $6 \%$ of the isolates to exhibit nonsusceptibility against doripenem and meropenem [34]. Along with these routinely administered carbapenems, administration of ertapenem induced no impact on the susceptibility pattern of imipenem and was directly associated with the reduced use of imipenem and ciprofloxacin among A. baumannii [35]. However, this study 
limits per se the omission of ertapenem under carbapenem-resistant profile for the test organisms under the study.

Phenotypic detection of MBL production was observed using IMP and IMP/ EDTA potentiation disc test. Among the tested isolates, with $100 \%$ resistance against imipenem and nearly $63 \%$ resistance against doripenem and meropenem, phenotypic confirmation was achieved only in $42.46 \%$ of the isolates. In addition, DDST positivity co-related only with $31.50 \%(n=23)$ of the isolates confirmed by Kirby-Bauer diffusion assay. Among the 73 imipenem-resistant isolates, only 31 were DDST-positive, which might be due to the $b l a_{\text {IMP }}$ gene cassettes associated with integrons that do not phenotypically express the $b l a_{\mathrm{IMP}}$ type of genetic determinants [36]. About $21.91 \%$ and $9.58 \%$ of the isolates among 31 DDSTpositive $A$. baumannii, expressing $b l a_{\mathrm{VIM}}$ and $b l a_{\mathrm{GIM}}$, suggest the role of VIM- and GIM-type $\beta$-lactamases in inducing carbapenem resistance. Although variants of IMP and VIM are frequently reported, MBL genetic determinants can be restricted to certain geographical regions with members of SPM, GIM, and SIM variants [37]. Genotypic characterization of MBL determinants with phenotypic-positive DDST showing 6 and 19 negative isolates may be again related to the variants exhibited among class I integron structures, which are frequently detected among A. baumannii $[38,39]$. Comparative analysis between phenotypic and genotypic data observed in the present investigation suggests DDST to be highly reliable and easy to perform for the preliminary screening of MBL production with the reports varying from $7.5 \%$ [40] to $70.9 \%$ [27].

Molecular detection of the genetic determinants of MBL production such as $b l a_{\mathrm{VIM}}, b l a_{\mathrm{IMP}}, b l a_{\mathrm{GIM}}$, and $b l a_{\mathrm{NDM}}$ was observed using PCR. All the imipenemresistant isolates $(n=73)$ of $A$. baumannii showed bla $_{\mathrm{IMP}}$ and bla $a_{\mathrm{NDM}}$ negative. In comparison with the carbapenem-resistant profile (imipenem - 100\%, doripenem $61.64 \%$, and meropenem $-67.12 \%)$ and DDST-positive isolates $(n=31)$, only 25 $(34.24 \%)$ and $12(16.43 \%)$ showed the presence of $b l a_{\mathrm{VIM}}$ and $b l a_{\mathrm{GIM}}$. This variation might be due to the other non-enzymatic mechanisms, such as presence of efflux pumps, role of outer membrane proteins etc., exhibiting the carbapenem resistance property among $A$. baumannii [41]. A widespread distribution of MBL producers among A. baumannii is observed worldwide such as $70 \%-90 \%$ in India, $27.1 \%$ in Pakistan, and considerable numbers in Europe, Australia, and Africa [42, 43].

Among the MBL genetic determinant, co-occurrences of the genes are also not uncommon. The studies record the different patterns of co-occurring MBL genes from different countries [44]. In view with this, the present study also records the co-occurrence of $b l a_{\mathrm{VIM}}$ and $b l a_{\mathrm{GIM}}$ in two isolates $(2.73 \%)$. Comparative analysis between phenotypic and genotypic detection also shows a significant report. The study records $21.91 \%(n=16)$ and $9.58 \%(n=7)$ with DDST $+b l a_{\mathrm{VIM}}$ and DDST $+b l a_{\mathrm{GIM}}$ positivity, respectively, with one $1.36 \%$ of 
the isolate showing DDST $+b l a_{\mathrm{VIM}}+b l a_{\mathrm{GIM}}$ positivity. In an earlier study from Nepal, co-existence of $b l a_{\mathrm{OXA}-23}$ and $b l a_{\mathrm{NDM}-1}$ was detected [45] with the presence of other class B MBLs, such as bla $a_{\mathrm{VIM}}$ and $b l a_{\mathrm{GIM}}$. One of the recent studies showed the presence of $b l a_{\mathrm{VIM}}$ only in imipenem-resistant genomic species of $13 \mathrm{TU}-A$. baumannii and not in other isolates [46]. These results when compared with the present investigation vividly portray the differences in the phenotypic and genotypic traits against the carbapenems among the $A$. baumannii species existing in different geographic locale.

A. baumannii traits acquire different kinds of antimicrobial resistance and are emerging as a dreadful nosocomial pathogen leading to complications in the treatment and control. Frequency of MBLs and the distribution of their genetic determinants restrict the administration of carbapenems against A. baumannii. Thus, this study concludes by stating the need for the proper and periodical antimicrobial surveillance programs for using carbapenems against $A$. baumannii isolates, as there exists a variation in the resistance pattern and the associated genes in inducing the carbapenemase resistance.

\section{Acknowledgements}

The authors are grateful to Dr. Senthil Pragash Dandapany ( $\mathrm{PhD}$ candidate, MAHER), Associate Professor, Department of Microbiology, Melmaruvathur Adhiparasakthi Institute of Medical Sciences and Research, Tamil Nadu, for rendering the culture strains for the study.

\section{Conflict of Interest}

None.

\section{References}

1. Bergogne-Berezin, E. B., Towner, K. J.: Acinetobacter spp. as nosocomial pathogens: Microbiological, clinical, and epidemiological features. Clin Microbiol Rev 9, 148-165 (1996).

2. Talbot, G. H., Bradley, J., Edwards, J. E., Gilbert, D., Scheld, M., Bartlett, J. G.: Bad bugs need drugs: An update on the development pipeline from the Antimicrobial Availability Task Force of the Infectious Diseases Society of America. Clin Infect Dis 42, 657-668 (2006).

3. Poirel, L., Nordmann, P.: Carbapenem resistance in Acinetobacter baumannii: Mechanisms and epidemiology. Clin Microbiol Infect 12, 826-836 (2006).

4. Richet, H. M., Mohammed, J., McDonald, L. C.: Building communication networks: International network for the study and prevention of emerging antimicrobial resistance. Emerg Infect Dis 7, 319-322 (2001). 
5. Ehlers, M. M., Hughes, J. M., Kock, M. M.: Prevalence of carbapenemase resistance in Acinetobacter baumannii. In Pana, M. (ed): Antibiotic Resistant Bacteria - A Continuous Challenge in The New Millennium. Intech Open, Europe, 2012, pp. 213-246.

6. Heritier, C., Poirel, L., Lambert, T., Nordmann, P.: Contribution of acquired carbapenemhydrolyzing oxacillinases to carbapenem resistance in Acinetobacter baumannii. Antimicrob Agents Chemother 49, 3198-3202 (2005).

7. Liakopoulos, A., Mavroidi, A., Katsifas, E., Theodosiou, A., Karagouni, A. D., Miriagou, V.: Carbapenemase-producing Pseudomonas aeruginosa from central Greece: Molecular epidemiology and genetic analysis of class I integrons. BMC Infect Dis 13, 505 (2013).

8. Rizek, C., Fu, L., Dos Santos, L. C., Leite, G., Ramos, J., Rossi, F., Guimaraes, T., Levin, A. S., Figueiredo Costa, S.: Characterization of carbapenem-resistant Pseudomonas aeruginosa clinical isolates, carrying multiple genes coding for this antibiotic resistance. Ann Clin Microbiol Antimicrob 13, 43 (2014).

9. Schlesinger, S. R., Lahousse, M. J., Foster, T. O., Kim, S. K.: Metallo- $\beta$-lactamases and aptamer-based inhibition. Pharmaceuticals 4, 419-428 (2011).

10. Noori, M., Karimi, A., Fallah, F.: High prevalence of metallo-beta-lactamase producing Acinetobacter baumannii isolated from two hospitals of Tehran, Iran. Arch Pediat Infect Dis 2, e15439 (2014).

11. King, D., Strynadka, N.: Crystal structure of New Delhi metallo- $\beta$-lactamase reveals molecular basis for antibiotic resistance. Protein Sci 20, 1484-1491 (2011).

12. Walsh, T. R., Toleman, M. A., Poirel, L., Nordmann, P.: Metallo-beta-lactamases: The quiet before the storm. Clin Microbiol Rev 18, 306-325 (2005).

13. Amudhan, M. S., Sekar, U., Kamalanathan, A., Balaraman, S.: bla $a_{\mathrm{IMP}}$ and $b l a_{\mathrm{VIM}}$ mediated carbapenem resistance in Pseudomonas and Acinetobacter species in India. J Infec Dev Ctries 6, 757-762 (2012).

14. Cornaglia, G., Giamarellou, H., Rossolini, G. M.: Metallo- $\beta$-lactamases: A last frontier for $\beta$-lactams? Lancet Infect Dis 4, 381-393 (2011).

15. Jones, R. N., Biedenbach, D. J., Sader, H. S., Fritsche, T. R., Toleman, M. A., Walsh, T. R.: Emerging epidemic of metallo-beta-lactamase mediated resistances. Diagn Microbiol Infect Dis 51, 77-84 (2005).

16. Lee, K., Yum, J. H., Yong, D., Lee, M., Kim, H. D., Docquier, J. D., Rossolini, G. M., Chong, Y.: Novel acquired metallo-beta-lactamase gene, bla $_{\mathrm{SIM}-1}$, in a class 1 integron from Acinetobacter baumannii clinical isolates from Korea. Antimicrob Agents Chemother 49, 4485-4491 (2005).

17. Göttig, S., Pfeifer, Y., Wichelhaus, T. A., Zacharowski, K., Bingold, T., Averhoff, B., Brandt, C., Kempf, V. A.: Global spread of New Delhi metallo-beta-lactamase 1. Lancet Infect Dis 10, 828-829 (2010).

18. Kaase, M., Nordmann, P., Wichelhaus, T. A., Gatermann, S. G., Bonnin, R. A., Poirel, L.: NDM-2 carbapenemase in Acinetobacter baumannii from Egypt. J Antimicrob Chemother 66, 1260-1262 (2011).

19. Lee, K., Lim, Y. S., Yong, D., Yum, H., Chong, Y.: Evaluation of the Hodge test and the imipenem-EDTA double disk synergy test for differentiating metallo- $\beta$-lactamase producing isolates of Pseudomonas spp. and Acinetobacter spp. J Clin Microbiol 41, 4623-4629 (2003).

20. Srinivasan, V. B., Rajamohan, G., Pancholi, P., Stevenson, K., Tadesse, D., Patchanee, P., Marcon, M., Gebreyes, W. A.: Genetic relatedness and molecular characterization of 
multidrug resistant Acinetobacter baumannii isolated in central Ohio, USA Gebreyes. Ann Clin Microbiol Antimicrob 8, 21 (2009).

21. Clinical Laboratory Standards Institute (CLSI): Performance standards for antimicrobial susceptibility testing. Table 3A: M02-A12 and M07-A10. CLSI, Wayne, PA, 2012.

22. Maleki, M. H., Sekawi, Z., Soroush, S., Azizi-Jalilian, F., Asadollahi, K. H., Mahammadi, S., Emaneini, M., Taherikalani, M.: Phenotypic and genotypic characteristics of tetracycline resistant Acinetobacter baumannii isolates from nosocomial infections at Tehran hospitals. Iran J Basic Med Sci 17, 21-26 (2014).

23. Singla, P., Sikka, R., Deep, A., Chaudhary, U.: Phenotypic detection and prevalence of MBLs in carbapenem resistant isolates of Acinetobacter species at a tertiary care hospital in North India. Int J Pharma Med Bio Sci 2, 2278-5221 (2013).

24. Anwar, M., Ejaz, H., Zafar, A., Hamid, H.: Phenotypic detection of metallo-beta-lactamases in carbapenem resistant Acinetobacter baumannii isolated from pediatric patients in Pakistan. J Pathog 2016, 8603964 (2016).

25. Kabbaj, H., Seffar, M., Belefquih, B.: Prevalence of metallo- $\beta$-lactamases producing Acinetobacter baumannii in a Moroccan hospital. ISRN Infect Dis 2013, 154921 (2013).

26. Khorsi, K., Messai, Y., Hamidi, M., Ammari, H., Bakour, R.: High prevalence of multidrug-resistance in Acinetobacter baumannii and dissemination of carbapenemaseencoding genes bla $_{\text {OXA-23-like, }}$ bla $a_{\text {OXA-24-like }}$ and bla $_{\text {NDM-1 }}$ in Algiers hospitals. Asian Pac J Trop Med 8, 438-446 (2015).

27. Uma Karthika, R., Srinivasa Rao, R., Sahoo, S., Shashikala, P., Kanungo, R., Jayachandran, S., Prashanth, K.: Phenotypic and genotypic assays for detecting the prevalence of metallo-beta-lactamases in clinical isolates of Acinetobacter baumannii from a South Indian tertiary care hospital. J Med Microbiol 58, 430-435 (2009).

28. Hussein, H. N., Al-Mathkhury, J. F. H., Sabbah, A. M.: Imipenem resistant Acinetobacter baumannii isolated from patients and hospitals environment in Baghdad. Iraq J Sci 54, 803-812 (2013).

29. Daef, E. A., Mohamed, I. S., Ahmed, A. S., El-Gendy, S. G., Sayed, I. M.: Detection of outbreak caused by multidrug resistant Acinetobacter baumannii in Assiut University hospitals. Afr J Microbiol Res 8, 2238-2244 (2014).

30. Taneja, N., Maharwal, S., Sharma, M.: Imipenem resistance in non-fermenters causing nosocomial urinary tract infections. Indian J Med Sci 57, 294-299 (2003).

31. Sinha, M., Srinivasa, H.: Mechanisms of resistance to carbapenems in meropenem resistant Acinetobacter isolates from clinical samples. Indian $\mathrm{J}$ Med Microbiol 25, 121-125 (2007).

32. Terzi, H. A., Atasoy, A. R., Aykan, S. B., Karakece, E., Asik, G., Ciftci, H. I.: Association of doripenem resistance with OXA-type carbapenemases in Acinetobacter baumannii isolates. Saudi Med J 37, 43-47 (2016).

33. Esterly, J. S., Qi, C., Malczynski, M., Scheetz, M. H.: Predictability of doripenem susceptibility in Acinetobacter baumannii isolates based on other carbapenem susceptibilities and $b l a_{\text {OXA }}$ gene status. Pharmacotherapy 30, 354-360 (2010).

34. Goyal, K., Gautam, V., Ray, P.: Doripenem vs meropenem against Pseudomonas and Acinetobacter. Indian J Med Microbiol 30, 350-351 (2012).

35. Sousa, D., Castelo-Corral, L., Gutiérrez-Urbón, J. M., Molina, F., López-Calviño, B., Bou, G., Llinares, P.: Impact of ertapenem use on Pseudomonas aeruginosa and Acinetobacter 
baumannii imipenem susceptibility rates: Collateral damage or positive effect on hospital ecology? J Antimicrob Chemother 68, 1917-1925 (2013).

36. Da Silva, G. J., Correia, M., Vita, C., Ribeiro, G., Sousa, J. C., Leitao, R., Peixe, L., Duarte, A.: Molecular characterization of bla $_{\mathrm{IMP}-5}$, a new integron-borne metallo- $\beta$-lactamase gene from an Acinetobacter baumannii nosocomial isolate in Portugal. FEMS Microbiol Lett 215, 33-39 (2002).

37. Ellington, M. J., Kistler, J., Livermore, D. M., Woodford, N.: Multiplex PCR for rapid detection of genes encoding acquired metallo-beta-lactamases. J Antimicrob Chemother 59, 321-322 (2007).

38. Seward, R. J.: Detection of integrons in worldwide nosocomial isolates of Acinetobacter spp. Clin Microbiol Infect 5, 308-318 (1999).

39. Gallego, L., Towner, K. J.: Carriage of class 1 integrons and antibiotic resistance in clinical isolates of Acinetobacter baumannii from northern Spain. J Med Microbiol 50, 71-77 (2001).

40. Gupta, V., Datta, P., Chander, J.: Prevalence of metallo- $\beta$-lactamase (MBL) producing Pseudomonas spp. and Acinetobacter spp. in a tertiary care hospital in India. J Infect 52, 311-314 (2006).

41. Limansky, A. S., Mussi, M. A., Viale, A. M.: Loss of a 29-kilodalton outer membrane protein in Acinetobacter baumannii is associated with imipenem resistance. J Clin Microbiol 40, 4776-4778 (2002).

42. Perry, J. D., Naqvi, S. H., Mirza, I. A., Alizai, S. A., Hussain, A., Ghirardi, S., Orenga, S., Wilkinson, K., Woodford, N., Zhang, J., Livermore, D. M., Abbasi, S. A., Raza, M. W.: Prevalence of faecal carriage of Enterobacteriaceae with NDM-1 carbapenemase at military hospitals in Pakistan, and evaluation of two chromogenic media. J Antimicrob Chemother 66, 2288-2294 (2011).

43. D’Andrea, M. M., Venturelli, C., Giani, T., Arena, F., Conte, V., Bresciani, P., Rumpianesi, F., Pantosti, A., Narni, F., Rossolini, G. M.: Persistent carriage and infection by multidrugresistant Escherichia coli ST405 producing NDM-1 carbapenemase: Report on the first Italian cases. J Clin Microbiol 49, 2755-2758 (2011).

44. Fallah, F., Noori, M., Hashemi, A., Goudarzi, H., Karimi, A., Erfanimanesh, S., Alimehr, S.: Prevalence of $b l a_{\mathrm{NDM}}, b l a_{\mathrm{PER}}, b l a_{\mathrm{VEB}}, b l a_{\mathrm{IMP}}$, and $b l a_{\mathrm{VIM}}$ genes among Acinetobacter baumannii isolated from two hospitals of Tehran, Iran. Scientifica 2014, 245162 (2014).

45. Joshi, P. R., Acharya, M., Kakshapati, T., Leungtongkam, U., Thummeepak, R., Sitthisak, S.: Co-existence of bla $a_{\mathrm{OXA} 23}$ and bla $a_{\mathrm{NDM} 1}$ genes of Acinetobacter baumannii isolated from Nepal: Antimicrobial resistance and clinical significance. Antimicrob Resist Infect Control 6, 21 (2017).

46. Lee, J. H., Choi, C. H., Kang, H. Y., Lee, J. Y., Kim, J., Lee, Y. C., Seol, S. Y., Cho, D. T., Kim, K. W., Song, D. Y., Lee, J. C.: Differences in phenotypic and genotypic traits against antimicrobial agents between Acinetobacter baumannii and Acinetobacter genomic species 13TU. J Antimicrob Chemother 59, 633-639 (2007). 